\title{
Measuring mode I cohesive law of wood bonded joints based on digital image correlation and fibre Bragg grating sensors
}

\author{
J. Xavier ${ }^{\mathrm{a}, \mathrm{b}, *}$, J.R.A. Fernandes ${ }^{\mathrm{c}, \mathrm{d}}$, O. Frazão ${ }^{\mathrm{d}}$, J.J.L. Morais ${ }^{\mathrm{a}}$ \\ ${ }^{a}$ CITAB, Departamento de Engenharias, Escola de Ciências e Tecnologia, Universidade de Trás-os-Montes e Alto Douro, Quinta de Prados, 5001-801 Vila Real, Portugal \\ ${ }^{\mathrm{b}}$ Optics and Experimental Mechanics Laboratory, INEGI, University of Porto Campus da FEUP, Rua Dr. Roberto Frias, 4200-465 Porto, Portugal \\ c Departamento de Física, Escola de Ciências e Tecnologia, Universidade de Trás-os-Montes e Alto Douro, Quinta de Prados, 5001-801 Vila Real, Portugal \\ ${ }^{\mathrm{d}}$ INESC TEC, Rua do Campo Alegre 687, 4169-007 Porto, Portugal
}

\section{A R T I C L E I N F O}

\section{Article history:}

Available online 13 November 2014

\section{Keywords:}

Wood

Adhesion

Mechanical testing

Joints/joining

\begin{abstract}
A B S T R A C T
This work addresses the experimental identification of mode I cohesive law of wood bonded joints. The approach combines the double cantilever beam (DCB) test with both digital image correlation (DIC) and embedded fibre Bragg grating (FBG) sensors. The spectrum geometric mean of the FBG reflected spectral response was determined, and the wavelength evolution was used to define the fracture process zone (FPZ) development phase. This evaluation allowed a consistent selection of experimental range of over which the identification procedure of mode I cohesive law is build up. Mode I crack length, Resistancecurve and cohesive law parameters are characterised and discussed. The strain energy release rate $\left(G_{\mathrm{I}}\right)$ is determined from the $P-\delta$ curve by the compliance-based beam method (CBBM). The crack tip opening displacement $\left(w_{\mathrm{I}}\right)$ is determined by post-processing displacements measured by DIC. The cohesive law in mode $\mathrm{I}\left(\sigma_{\mathrm{I}}-w_{\mathrm{I}}\right)$ is then obtained by numerical differentiation of the $G_{\mathrm{I}}-w_{\mathrm{I}}$ relationship.
\end{abstract}

() 2014 Elsevier Ltd. All rights reserved.

\section{Introduction}

Adhesive technologies have been playing an important role in new applications and innovation of modern wooden constructions. Although there have been great advances in the science and engineering of wood adhesion, the characterisation and modelling of the adhesive bond strength at the adherent wood interface remains an open problem. Moreover, the crack initiation and propagation in adhesives evolve into a fracture process zone (FPZ) ahead of the crack tip. An effective way to deal with such complex fracture phenomena and mechanisms is through cohesive zone models (CZM), conjointly with interface finite elements [1-4]. Accordingly, the entire FPZ is collapsed into the cohesive crack surfaces, being the material behaviour described by a cohesive law that relates the cohesive stresses to the relative displacements of the adjacent cohesive surfaces [3]. This approach has some advantages with regard to the classical fracture mechanics approach. A relevant one is the possibility to completely describe

\footnotetext{
* Corresponding author at: CITAB, Departamento de Engenharias, Escola de Ciências e Tecnologia, Universidade de Trás-os-Montes e Alto Douro, Quinta de Prados, 5001-801 Vila Real, Portugal. Tel.: +351 225082 150; fax: +351 225081 584.

E-mail address: jxavier@inegi.up.pt (J. Xavier).
}

the fracture event, starting from the undamaged material, without the presence of an initial crack and it is not almost mesh independent.

Although the widespread use of CZM, the experimental identification of the cohesive laws poses several difficulties. One way of tackling this problem is by an inverse method, in which a particular shape for the cohesive law is assumed and its constitutive parameters determined from global experimental tests using optimisation procedures [5-7]. However, this type of indirect identification method is impaired with an important limitation. Indeed, the a priori choice of a shape for the cohesive law does not guarantee its transferability from the laboratory tests to an arbitrary geometry. Moreover, this approach can be computationally time consuming and the uniqueness of the minimisation problem is not guaranteed. In order to overcome these drawbacks, several authors [8-11] have developed direct methods to identify the cohesive law without any prerequisite assumption about its shape. They are based on the simultaneous measurement of the crack opening displacement (COD) and the related strain energy release rate $(G)$ during the fracture test. The cohesive law comes up through the differentiation of $G$ versus COD relationship. This approach was recently applied to wood and composites bonded joints under both mode I $[6,12,13]$ and mode II $[14,15]$ loading. The opening displacement at the initial crack tip (CTOD) was 
evaluated by post-processing the crack tip displacements measured by means of digital image correlation (DIC) [16,17], whereas Resistance-curves ( $R$-curves) were determined using the compliance-based beam method (CBBM) [5]. However, the identification of the cohesive law must be obtained from the experimental response of the specimen during the development of the FPZ, i.e., after the initial elastic response of the specimen up to the self-similar crack propagation. Hence, a central issue in determining the cohesive law directly from load $(P)$, load-point displacement $(\delta)$ and CTOD is the clear identification of the FPZ development phase. In the case of bonded joints, embedded fibre Bragg grating (FBG) sensors can be a feasible way to accomplish this goal [18].

A direct method for evaluating the cohesive laws of Pinus pinaster Ait. wood bonded joints under mode I is examined in the present work. The double cantilever beam (DCB) test was selected. The identification method requires the continuous monitoring of CTOD and the evaluation of the strain energy release rate in mode I $\left(G_{I}\right)$. A simple data reduction scheme (CBBM) based on the elastic crack equivalent concept $\left(a_{\mathrm{e}}\right)$ is used to determine the evolution of $G_{I}$ during the test. DIC was employed for determine CTOD in mode I $\left(w_{\mathrm{I}}\right)$. An FBG sensor embedded in the glue line, at the initial crack tip, was employed in order to assist in the identification of FPZ development phase. These measurements were analysed in view of the direct identification of mode I cohesive law of wood bonded joints.

\section{Mode I cohesive law}

The DCB test, coupled with DIC and FGB measurements, is schematically shown in Fig. 1 . The specimen consists of two $L \times h \times B$ rectangular beams, glued by an adhesive with thickness $t$. Moreover, an initial crack length $a_{0}$ is assumed in the reference configuration. The basic equation to evaluate $G_{I}$ is the Irwin-Kies equation,

$G_{\mathrm{I}}=\frac{P^{2}}{2 B} \frac{\mathrm{d} C}{\mathrm{~d} a}$

where $C$ and $a$ are the specimen compliance and crack length in the current configuration, respectively. The CBBM is a straightforward data reduction scheme to determine $\mathrm{d} C / \mathrm{d} a$, circumventing the previous calibration of specimen compliance or the monitoring of crack length during the fracture test $[5,19]$. Furthermore, the CBBM is suitable to deal with the variability of elastic properties, which is particularly important for biological materials. Considering the Timoshenko beam theory and the Castigliano theorem, it can be shown that $C$ is given explicitly as a function of $a$ by the following relationship [5]

$C=\frac{8 a^{3}}{B h^{3} E_{\mathrm{L}}}+\frac{12 a}{5 B h G_{\mathrm{LR}}}$

where $E_{\mathrm{L}}$ and $G_{\mathrm{LR}}$ represent the elastic longitudinal and shear moduli, respectively. By replacing the initial crack length and specimen compliance (i.e., $a_{0}$ and $C_{0}$ ) in Eq. (2), an equivalent elastic modulus $\left(E_{\mathrm{f}}\right)$ can be obtained that accounts for the presence of adhesive, material variability between specimens and stress concentration in the vicinity of the crack tip

$E_{\mathrm{f}}=\frac{8\left(a_{0}+h \Delta\right)^{3}}{B h^{3}}\left(C_{0}-\frac{12\left(a_{0}+h \Delta\right)}{5 B h G_{\mathrm{LR}}}\right)^{-1}$

where $\Delta$ is a crack length correction that accounts for root rotation elastic effects. This parameter can be obtained numerically in two steps [20]. Firstly, the initial compliance is adjusted for the considered $a_{0}$. Secondly, two numerical simulations considering two different initial crack lengths must be performed in order to establish the $C^{1 / 3}=f(a)$ relation. The interception of this line with the abscissa axis allows the evaluation of $\Delta$. During the crack propagation, Eq. (2) can be used to determine the equivalent elastic crack length $\left(a_{\mathrm{e}}\right)$ from the current specimen compliance $(C)$, taking into account $E_{f}$ (Eq. (3)) instead of $E_{L}$. The $R$-curve in mode I can therefore be obtained combining the Irwin-Kies equation (1) with Eq. (2) yielding

$G_{\mathrm{I}}=\frac{6 P^{2}}{B^{2} h}\left(\frac{2 a_{\mathrm{e}}^{2}}{E_{\mathrm{f}} h^{2}}+\frac{1}{5 G_{\mathrm{LR}}}\right)$

It should be referred that $G_{\mathrm{LR}}$ has a minor influence on the results [5] which means that a typical value can be used. Experimentally, the elastic properties of wood can be determined from both quasi-pure mechanical tests such as off-axis, Iosipescu and Arcan $[21,22]$ or heterogeneous tests such as the unnotched Iosipescu test $[23,24]$ or annual ring-pattern tests [25].
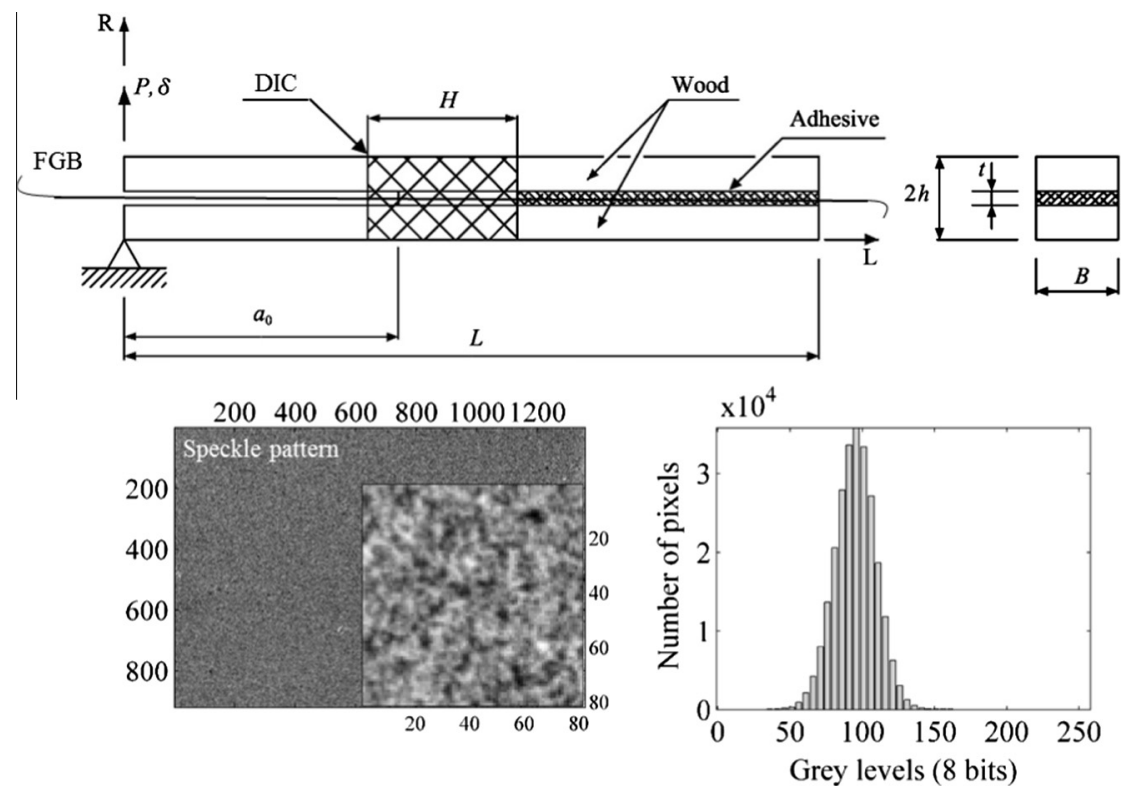

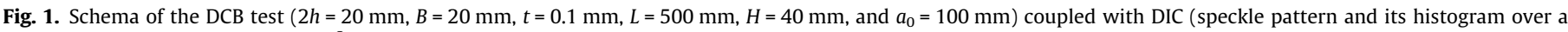
region of interest of $\left.24.5 \times 16.6 \mathrm{~mm}^{2}\right)$ and $\mathrm{FBG}$. 
The direct identification of the cohesive law in mode I requires the measurement of CTOD, with a suitable technique such as DIC. The cohesive law arises from the differentiation of $G_{I}$ with respect to the CTOD $\left(w_{\mathrm{I}}\right)$

$\sigma_{\mathrm{I}}\left(w_{\mathrm{I}}\right)=\frac{\mathrm{d} G_{\mathrm{I}}}{\mathrm{d} w_{\mathrm{I}}}$

A suitable differentiation algorithm must be used to avoid noise amplification in the reconstruction of the constitutive cohesive law. In order to apply Eq. (5), it is proposed to fit the $G_{I}-w_{I}$ data by a continuous function described by the following expression (logistic function)

$G_{\mathrm{I}}=\frac{A_{1}-A_{2}}{1+\left(w_{\mathrm{I}} / w_{\mathrm{I}, 0}\right)^{p}}+A_{2}$

where $A_{1}, A_{2}, p$ and $w_{\text {II, } 0}$ are constants to be determined by non-linear least-square regression [26]. In this function, the $A_{2}$ parameter must provide an estimation of the critical strain energy release rate in the sense that: $A_{2} \equiv G_{\mathrm{Ic}}$ when $w_{\mathrm{I}} \rightarrow \infty$.

\section{Experimental work}

\subsection{Material and testing}

The wood material used in this work was taken from a single Pinus pinaster Ait. tree. Matched beams were cut from mature wood to mitigate material variability. DCB wood-bonded joints specimens were then prepared with nominal dimensions of $2 h=20 \mathrm{~mm}, B=20 \mathrm{~mm}, t=0.1 \mathrm{~mm}, L=500 \mathrm{~mm}$ and an initial crack length of $a_{0}=100 \mathrm{~mm}$ (Fig. 1 ). The wood surfaces were firstly clean and polished using sandpaper to enhance adhesion with the epoxy adhesive (Araldite ${ }^{\circledR} 2015$ ). The pre-crack surface within the adhesive was introduced by means of a thin Teflon ${ }^{\circledR}$ film (thickness of $25 \mu \mathrm{m}$ ).

The DCB fracture tests were carried out in a screw-driven Instron ${ }^{\circledR} 1125$ testing machine at crosshead displacement rate of $5 \mathrm{~mm} / \mathrm{min}$. The applied load was measured by means of a $100 \mathrm{kN}$ load cell. The load $(P)$ and the crosshead displacement of the testing machine $(\delta)$ were recorded during the test by means of a National Instruments ${ }^{\circledR}$ USB-6210 daq card controlled using Labview $^{\circledR}$, with a sampling rate of $10 \mathrm{~Hz}$, connected to the analogue outputs of the testing machine. In order to define the $G_{I}=f(w)$ function, the displacement fields at the crack tip during the fracture tests were measured by DIC as described in the following.

\subsection{Digital image correlation}

DIC is a full-field optical technique in which displacements at discrete data points are provided by correlating images at different mechanical configurations [27]. The deformation of the material is evaluated by means of the deformation of a textured pattern, assumed perfectly attached to the object surface. This technique has been developing in recent decades and is gradually becoming a general-proposed tool in experimental mechanics. The spatial resolution and accuracy of the technique can be adjusted by the optical components used in the image formation and size and step of correlation windows, in order to address engineering applications that can be scaled from structural to micro levels.

At the macro scale, the natural wood surface does not provide the required textured pattern for DIC measurements. A speckle pattern was then painted over a region of interest of $40(\mathrm{R}) \times 20(\mathrm{~T}) \mathrm{mm}^{2}$, around and ahead of the initial crack tip, by means of an airbrush, to guarantee suitable grain size, contrast and isotropy at the scale of observation (Fig. 1). The ARAMIS ${ }^{\circledR}$ DIC-2D system was used in this work $[28,29]$. A charged coupled digital (CCD) camera coupled with a telecentric lens was used for image grabbing. The optical system components and DIC measuring parameters are summarised in Table 1. According to the typical size of the painted speckle pattern, a subset size of $15 \times 15$ pixels $^{2}$ $\left(0.27 \times 0.27 \mathrm{~mm}^{2}\right)$ was chosen. This length defines the spatial resolution associated to the measurements (i.e., the smallest distance separating two independent measurements). The accuracy of the measurements was estimated experimentally based on translation rigid-body tests, from which displacement and strain fields are theoretically known $[29,30]$. At least a pair of images was recorded before and after applying a lateral translating of the camera-lens system using a $X-Y$ translation table. Typically, noise fields are obtained from image correlation, which can be modelled as a white Gaussian noise signal. Therefore, the standard deviation was defined as an estimation of the global accuracy associated to the optical measurements. A resolution in displacement of the order of $1-2 \times 10^{-2}$ pixel $(0.18-0.36 \mu \mathrm{m})$ was achieved.

The value of $w_{\mathrm{I}}$ must be determined locally at the initial crack tip with suitable spatial resolution and accuracy. A solution can be provided by post-processing DIC displacements according to the following relationship

$w_{\mathrm{I}}=\left\|w_{\mathrm{I}}^{+}-w_{\mathrm{I}}^{-}\right\|$

where $w_{\perp}^{+}$and $w_{1}^{-}$are the components of the displacement in the direction perpendicular to the crack propagation, associated to the upper and the lower cracked surface. Numerically, this parameter can be determined at superimposed nodes located at the initial crack tip of cohesive elements with zero thickness. Experimentally, this relative displacement was evaluated at a pair of subsets, chosen up and down the crack tip location, with a spatial resolution of $0.448 \mathrm{~mm}$.

\subsection{Fibre Bragg grating sensors}

Fibre optic FBGs have been used as a strain sensor in many engineering applications. One intrinsic advantage is related to the sensor dimension due to the fibre diameter $(125 \mu \mathrm{m}$ for a standard SMF28 fibre). For the purpose of this study, the FBG was conveniently embedded in the epoxy adhesive within the wooden joint. FBGs with a length of $6 \mathrm{~mm}$ were produced by the phase mask technique using a $\mathrm{KrF}$ excimer laser emitting $24 \mathrm{~ns}$ pulses with wavelength of $248 \mathrm{~nm}$. These sensors were manufactured by Fibersensing ${ }^{\circledR}$, with the Bragg peak at $1550 \mathrm{~nm}$ and a peak reflectivity higher than $90 \%$. The fibre with FBG was embedded in the glue line, during the specimen manufacture, ensuring that the sensor was positioned at the centre of initial crack tip and oriented along the longitudinal direction of specimen (Fig. 2). The correct alignment of optical fibre was ensured using dead weights attached to its extremities, while pressing the two arms of DCB specimen during the adhesive cure. The fibre was connected to a spectral analyser Fibersensing ${ }^{\circledR}$ Braggmeter FS2200SA that retrieved reflection spectra with a frequency of $0.5 \mathrm{~Hz}$. This system makes the FBG interrogation in the $1500-1600 \mathrm{~nm}$ range and can record simultaneously the reflection and transmission spectra. Both the spectral analyzer and the daq card were controlled by the same computer and all the data acquired by these two systems were temporally synchronised.

\section{Results and discussion}

Fig. 3 shows a $P-\delta$ curve obtained experimentally, which is representative of the typical behaviour observed. After the initial elastic response, the curve shows a non-linear behaviour before the maximum load is reached, which is attributed to the formation and growth of the FPZ ahead of the initial crack tip [31]. After this stage, a monotonically decreasing of the load is observed 
Table 1

Components of the optical system and digital image correlation measuring parameters.

\section{CCD camera \\ Model}

Shutter time

Acquisition frequency

Lens

Model

Magnification

Field of view $\left(1 / 1.8^{\prime \prime}\right)$

Working distance

Working F-number

Field depth

Conversion factor

Lighting

DIC measurements

Subset size

Subset step

Resolution
Baumer Optronic FWX20

( 8 bits, $1624 \times 1236$ pixels, $4.4 \mu \mathrm{m} /$ pixel)

$0.7 \mathrm{~ms}$

$1 \mathrm{~Hz}$

Opto Engineering Telecentric lens TC 2336

$0.243 \pm 3 \%$

$103.5 \pm 3 \mathrm{~mm}$

f/8

$11 \mathrm{~mm}$

$0.018 \mathrm{~mm} /$ pixel

Raylux 25 white-light LED

$15 \times 15$ pixel $^{2}\left(0.270 \times 0.270 \mathrm{~mm}^{2}\right)$

$13 \times 13$ pixel $^{2}\left(0.234 \times 0.234 \mathrm{~mm}^{2}\right)$

$1-2 \times 10^{-2}$ pixel $(0.18-0.36 \mu \mathrm{m})$
$29.3 \times 22.1 \mathrm{~mm}^{2}$

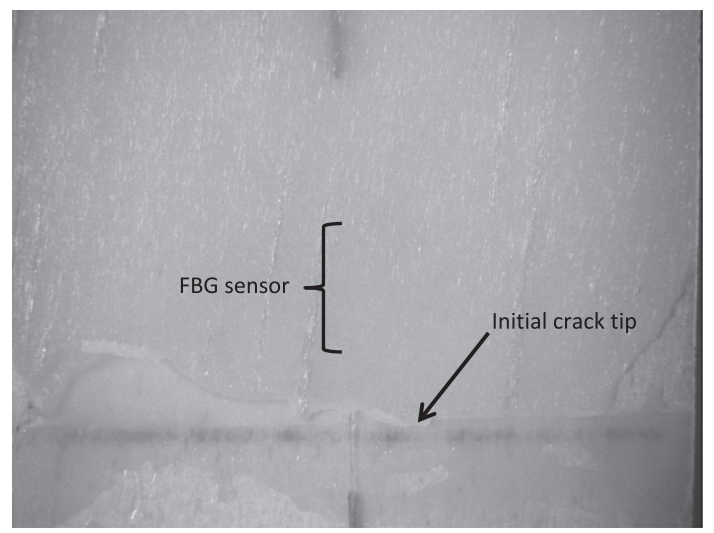

Fig. 2. FBG sensor location and typical failure of the wood bonded joints.

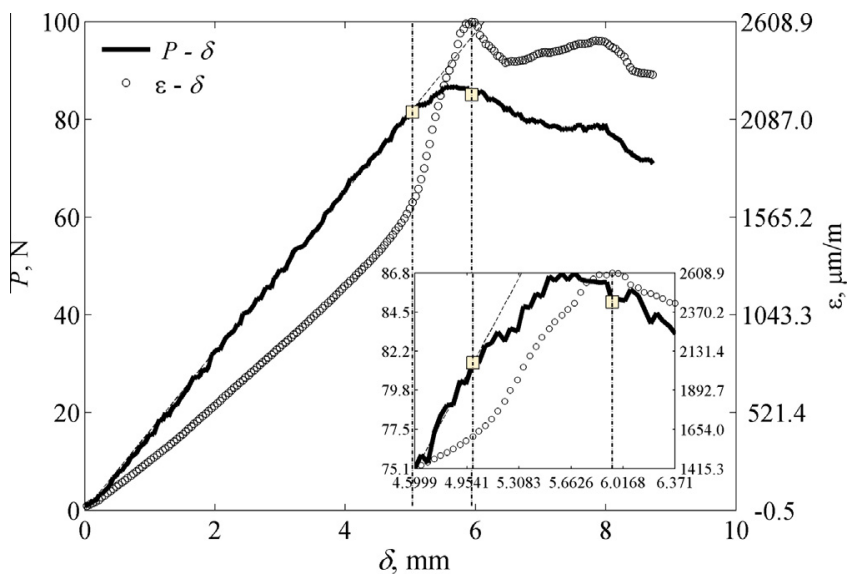

Fig. 3. Load-displacement and mean local strain-displacement curves.

corresponding to steady-state crack propagation. Fig. 4 shows the evolution of CTOD with regards to the applied displacement $(\delta)$ (for the same specimen of Fig. 3 ). In the CTOD- $\delta$ curve, three distinct regions can be distinguished in close relation with the $P-\delta$ one. In the first region, the CTOD increases at an almost constant rate, corresponding to the initial elastic response in the $P-\delta$ curve. The second region is characterised by a CTOD growth at increasing rate, and can be linked to the non-linear section of the $P-\delta$ curve

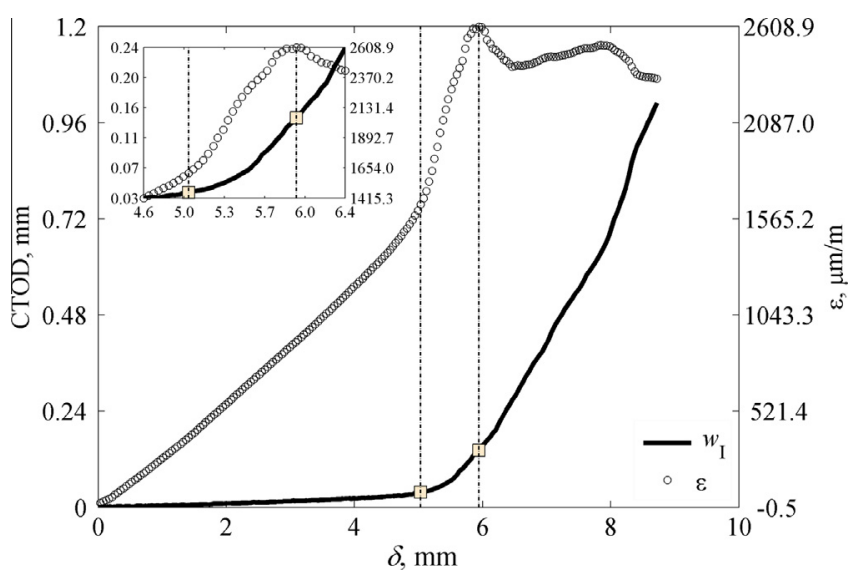

Fig. 4. CTOD-displacement and mean local strain-displacement curves.

before maximum load is reached. Hence, the behaviour of this second region of the CTOD- $\delta$ curve is conceivably a consequence of the development of the FPZ. The last region of CTOD- $\delta$ curve exhibits again a constant CTOD growth rate and is related to the monotonically decreasing region of $P-\delta$ curve associated to the steady-state crack propagation. The failure of all specimens takes place in the adhesive, as is shown in the photograph of Fig. 2.

The nature and sequence of damage events described above, inferred from the experimental $P-\delta$ and CTOD- $\delta$ curves, was also examined using the reflected spectral response of the FBG sensor embedded in the glue line at the initial crack tip. The typical FBG reflection spectrum evolution is shown in Fig. 5, in which the spectrum wavelength shift is plotted at three different applied loads. The change in the shape is a result of the high heterogeneous strain applied to the fibre in the FBG position by the glued joint. Just after the maximum applied load, the reflection spectrum returns to the original shape corresponding to the situation where the glued joint has collapsed and the crack propagated beyond the FBG position.

The reflection spectra are difficult to interpret due to peak splitting and the appearance of multiple reflection peaks of equivalent height [32]. Several methods have been proposed to reconstruct the multiaxial strain field applied to the FBG. However, these techniques are, in general, very time consuming and provide limited information of the specimen overall mechanical behaviour [33]. To determine the spectral shift the standard methods try to identify one maximum reflection peak per FBG and follow the position of this peak in time [34]. However, if the reflected spectrum is becoming highly deformed with multiple peaks splitting, each

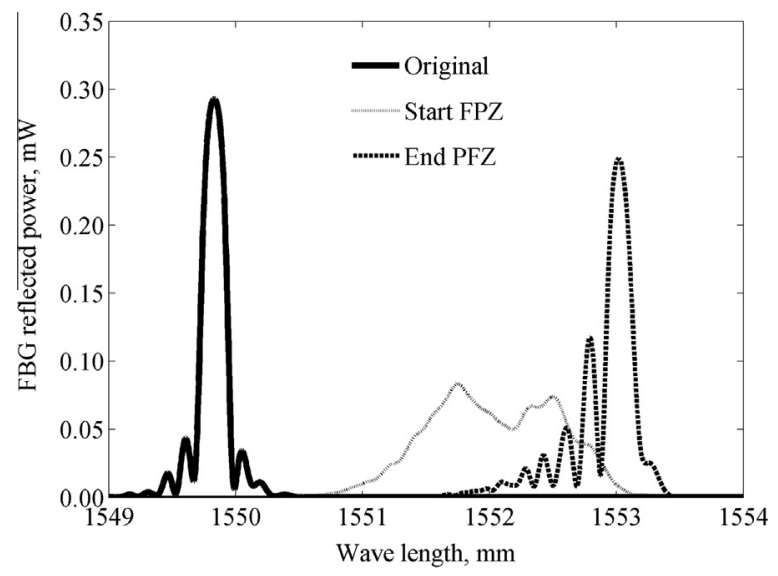

Fig. 5. Spectral responses at three stages of loading: at the beginning of test (original spectrum), at the onset of FPZ formation and at the end of full extension of FPZ. 
FBG will yield multiple peaks with equivalent heights resulting in inconsistent values for the spectrum wavelength shift evolution. It was also observed that the overall FBG spectral reflection response always moves toward higher wavelengths with the increase of applied deformation even if it was not possible to identify a predominant reflection peak that can be followed and used to quantify this overall wavelength shift. This problem was tackled by the use of an alternative method to quantify the FBG spectral wavelength shift using the equivalent to a spectral wavelength geometric mean ( $\lambda_{\mathrm{GM}}$ that can be determined for all the measured spectra. The evolution of this wavelength geometric mean can be followed in time and then related with the other macroscopic quantities measured simultaneously during the DCB test.

In this method, each spectrum is divided in $m$ optical power levels, between $10 \%$ and $95 \%$ of maximum FBG reflected power $\left(p_{\max }\right)$ The geometric mean of each power level $\left(p_{j}\right)$ is determined by

$\lambda_{j}^{\mathrm{avg}}=\sqrt[n]{\prod_{i=1}^{n} \lambda_{i}}$

using the $n$ wavelengths $\left(\lambda_{i}\right)$ that satisfy the inequality: $p_{i} \geqslant p_{j}$. The number of terms satisfying this condition will vary among power levels and, as a consequence, the root order will also vary accordingly. The final wavelength representing each spectrum is then determined by calculating the geometric mean of the wavelengths representing the $m$ power levels by

$\lambda_{\mathrm{GM}}=\sqrt[m]{\prod_{i=1}^{m} \lambda_{j}^{\mathrm{avg}}}$

By using this method the power distribution is taken into account because wavelengths with higher power levels will contribute more to the final mean value than wavelengths with lower power levels. Fig. 6 shows the evolution of spectral geometric mean for the different power levels and the final value for each of the two spectra presented. It should be noted that in non-deformed and symmetric FBG reflection spectra, $\lambda_{\mathrm{GM}}$ is identical to the measured by the standard methods of peak identification and determination, as it can be observed in the initial FBG spectra in Fig. 6, in particular when compared to the values returned by Braggmeter interrogation system.

The mean wavelength shift $\left(\Delta \lambda_{\mathrm{GM}}\right)$ is related to the mean local strain at the crack tip $(\varepsilon)$ by the following equation [35]:

$\varepsilon=\frac{1}{1-p_{e}} \frac{\Delta \lambda_{\mathrm{GM}}}{\lambda_{\mathrm{GM} 0}}$

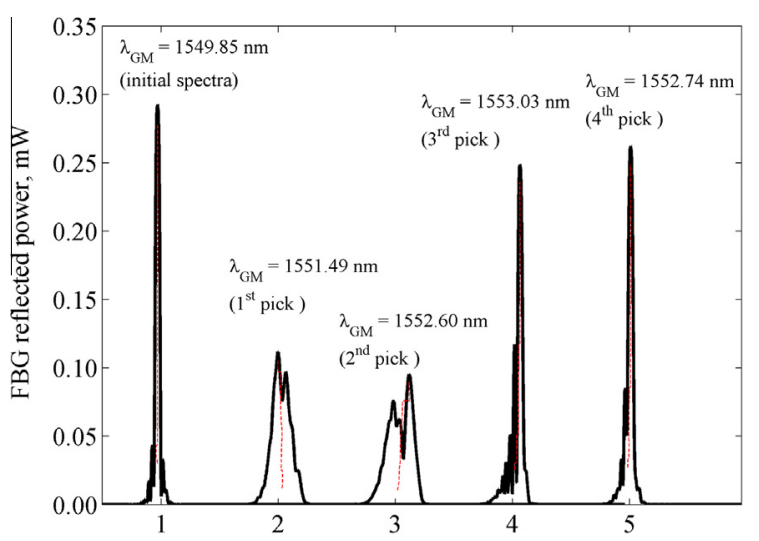

Fig. 6. Reflection spectra of an FBG with wavelength geometric mean for different power levels (red line inside the spectra) and the geometric mean of all power levels considered. (For interpretation of the references to color in this figure legend, the reader is referred to the web version of this article.) where $p_{e}=0.22$ is the photo-elastic coefficient for standard Gedoped optical fibres and $\lambda_{\mathrm{GM}}$ is the initial (before the fracture test) value of $\lambda_{\mathrm{GM}}$.

The variation of the mean local strain $(\varepsilon)$ with regard to the applied displacement $(\delta)$ is shown in Figs. 3 and 4, together with the $P-\delta$ curve and the CTOD- $\delta$ curve, respectively. A noticeable rise in the local strain rate is observed, in close agreement with the increase of CTOD growth rate (Fig. 4), after the end of the initial elastic segment of $P-\delta$ curve (Fig. 3 ). That change of local strain rate is understood as an indicator of the onset of FPZ development. Hence, the following criterion for the initiation of FPZ can be stated from the $\varepsilon-\delta$ curve: it is the displacement $\delta_{i}$ obtained from the intersection of two straight lines adjusted to the $\varepsilon-\delta$ data points, before and after the main slope augmentation of $\varepsilon-\delta$ curve. This criterion is translated to a point (square point) in the $P-\delta$ curve (Fig. 3 ) and in the CTOD- $\delta$ curve (Fig. 4), showing its consistency.

As it can be seen in Fig. 3, in the neighbourhood of the maximum load applied to the specimen (for this specimen, the square point slightly after the maximum load) the $\varepsilon-\delta$ curve attains a maximum value, which is followed by a negative slope. This negative slope represents a strain relaxation which could be attributed to the start of crack advance and to the end of FPZ. The displacement $\delta_{e}$ matching the maximum $\varepsilon$ value (or the first sign change of $\varepsilon-\delta$ slope) can be employed as a criterion to define the full development of FPZ. The CTOD value associated to $\delta_{e}$ is represented by a square point in Fig. 4. As it can be seen, this point is the boundary between the second and third regions of CTOD- $\delta$ curve discussed above.

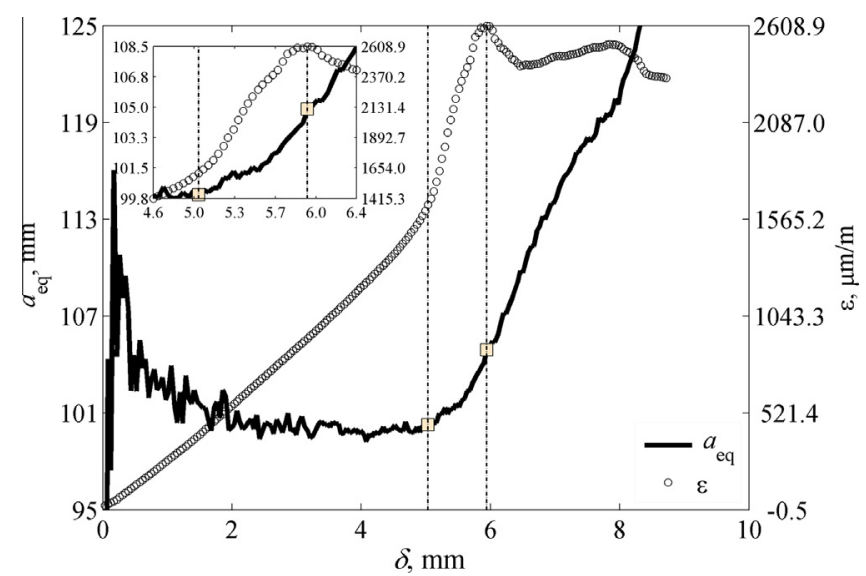

Fig. 7. Equivalent crack length versus displacement and mean local strain versus displacement curve.

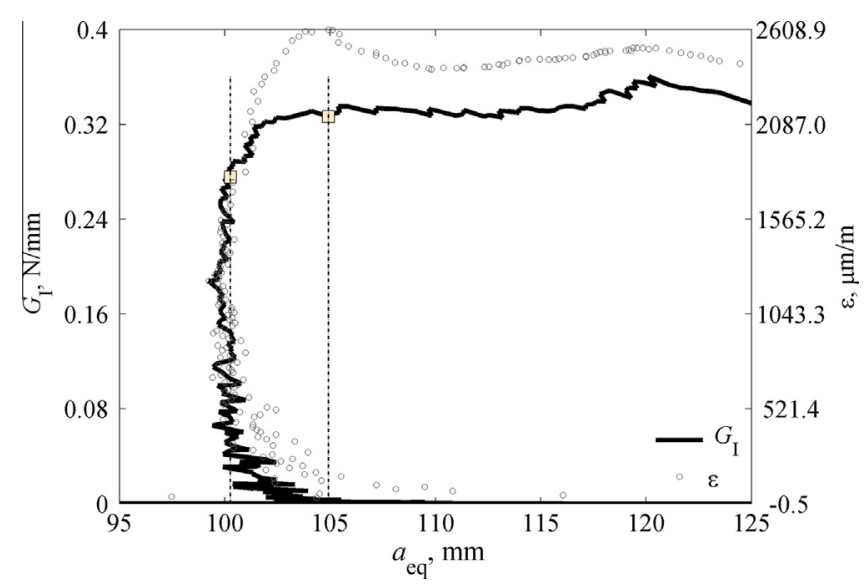

Fig. 8. Mode I resistance-curve and mean local strain versus equivalent crack length curve. 
The wavelength peak (or Bragg wavelength) is a very sensitive parameter and its value can be measured accurately when the applied strain is uniform along the grating, as shown in the original spectrum of Fig. 5. However, during the fracture test the spectral response becomes very complex due to the presence of nonuniform axial strains, displaying split-peak or multiple-peaks, with no simple means of interpretation. Moreover, the form of FBG reflection spectrum changes considerably during the fracture test, according to the local damage events. Fig. 4 shows the original spectrum (at the beginning of fracture test) along with the spectra at the limits of FPZ development, identified before (Figs. 3 and 4). Despite the complex form and evolution of FBG reflection spectrum throughout the fracture test, the geometric mean wavelength $\lambda_{\mathrm{GM}}$ (or the related local mean strain, obtained through Eq. (10)) proves to be an effective way to determine the limits, in terms of the independent testing variable (i.e. the applied displacement), of FPZ development. Therefore, the identification of mode I cohesive law should be performed using the P, $\delta$ and CTOD experimental values within those limits.

The first step in applying the CBBM is the evaluation of the equivalent elastic crack length $\left(a_{\mathrm{e}}\right)$ from the $P-\delta$ curve, using Eqs. (2) and (3). Fig. 7 shows the variation of $a_{\mathrm{e}}$ with the applied displacement, together with the $\varepsilon-\delta$ curve. The first significant value of $a_{\mathrm{e}}$ occurs at the onset of FPZ (first square mark in Fig. 7) and is equal to the initial crack length $\left(a_{0}\right)$. In the early stages of linear elastic response of specimens the calculated values of $a_{\mathrm{e}}$ are noisily and its evolution with the applied displacement is meaningless. It should be noticed that $a_{\mathrm{e}}$ was calculated from the current compliance (Eq. (2)), on a point-by-point basis. After the onset of FPZ, $a_{\mathrm{e}}$

\section{Table 2}

Evaluation of the equivalent crack length during FPZ development phase $\left(\Delta a_{\mathrm{e}}\right)$ and initial $(i)$ critical $(c)$ and at maximum load $\left(P_{\max }\right)$ strain energy release rate $\left(G_{\mathrm{I}}\right)$ of $P$. pinaster wood bonded joints.

\begin{tabular}{cllll}
\hline Specimen & $\Delta a_{\mathrm{eq}}(\mathrm{mm})$ & $G_{\mathrm{Ii}}(\mathrm{N} / \mathrm{mm})$ & $G_{\mathrm{Ic}}(\mathrm{N} / \mathrm{mm})$ & $G_{\mathrm{I}, \mathrm{Pmax}}(\mathrm{N} / \mathrm{mm})$ \\
\hline 1 & 3.149 & 0.335 & 0.430 & 0.435 \\
2 & 13.1 & 0.289 & 0.514 & 0.464 \\
3 & 5.134 & 0.252 & 0.326 & 0.318 \\
4 & 9.022 & 0.265 & 0.484 & 0.508 \\
5 & 3.843 & 0.211 & 0.412 & 0.460 \\
6 & 4.734 & 0.111 & 0.224 & 0.224 \\
7 & 3.144 & 0.252 & 0.371 & 0.368 \\
8 & 4.695 & 0.148 & 0.253 & 0.253 \\
9 & 4.740 & 0.214 & 0.309 & 0.312 \\
10 & 13.7 & 0.210 & 0.448 & 0.369 \\
11 & 4.625 & 0.183 & 0.348 & 0.348 \\
Mean & 6.347 & 0.225 & 0.374 & 0.364 \\
Std & 3.807 & 0.064 & 0.093 & 0.088 \\
C.V. ${ }^{1}$ (\%) & 60.0 & 28.3 & 24.8 & 24.1 \\
\hline
\end{tabular}

${ }^{1}$ Coefficient of variation (C.V.). advances at a growing rate, until a constant propagation rate is achieved. It is remarkably noted that the transient region of equivalent crack propagation (i.e., the region where $\mathrm{d} a_{\mathrm{e}} / \mathrm{d} t$ is growing) matches with the FPZ development identified in the $\varepsilon-\delta$ curve. This behaviour was systematically observed among the tested specimens. The second step of the data reduction is the evaluation of the $R$-curve by applying Eq. (4) to $(\delta, P)$ experimental data. The obtained results can be seen in Fig. 8 , where the $\lambda_{\mathrm{GM}}$ versus $a_{\mathrm{e}}$ relationship is also superimposed. An initial $\left(G_{\mathrm{Ii}}\right)$ and critical $\left(G_{\mathrm{Ic}}\right)$ strain energy release rates in mode I were evaluated from the $R$-curves afterwards. $G_{\mathrm{Ii}}$ is assumed to be the value of strain energy release rate at $\delta_{i}$ (i.e., at the onset of FPZ: first square mark in Fig. 8), whereas $G_{\text {Ic }}$ is assumed to be the strain energy release rate at $\delta_{e}$, just before steady-state crack propagation (i.e., at the end of FPZ development: second square mark in Fig. 8). It is worth noticing that the $\varepsilon-a_{e}$ curve exhibits the same trend of the $R$-curve, in the pre-FPZ development region and in the post-FPZ development region.

Table 2 summarises the results of the equivalent crack length during FPZ development phase $\left(\Delta a_{\mathrm{e}}\right)$, initial $\left(G_{\mathrm{Ii}}\right)$ and critical $\left(G_{\mathrm{Ic}}\right)$ strain energy release rates, extracted from the $R$-curve at the boundaries of the FPZ development as described above. Table 2 also contains the results of strain energy release rate for the maximum load $\left(G_{\mathrm{I}, \mathrm{Pmax}}\right)$, for comparison purposes. An average value of $\Delta a_{\mathrm{e}}=6.347 \mathrm{~mm}$ is obtained for the FPZ extension. In terms of $G_{\mathrm{I}}$, taking into account the scatter of those results, the mean value of $G_{I, P \max }$ can be taken as a practical measure of the mode I critical strain energy release rate.

Fig. 9a shows the $G_{I}=f\left(w_{I}\right)$ curve obtained by combining CBBM and DIC measurements. This curve is the basic information required for the direct identification of the cohesive law (Eq. (5)). A continuous function (in this work, the logistic function, Eq. (6)) was used to approximate the data points in the reconstructing process of the cohesive law, as shown in Fig. 9a. This procedure allows filtering the experimental data before analytical differentiation, thus circumventing the noise amplification characteristic of numerical differentiation. Only the data points within the limits of FPZ development were taken into account in the regression analysis. The cohesive laws were then determined by analytical differentiation of the logistic approximation function, as shown in Fig. 9b.

Table 3 summarises the following parameters of cohesive law: the area under the cohesive law (which is a measure of critical strain energy release rate, $G_{I, a r e a}$ ), the maximum cohesive stress $\left(\sigma_{\mathrm{u}}\right)$ and the maximum or critical CTOD $\left(w_{\mathrm{Ic}}\right)$. The mean value of $G_{\text {I,area }}$ (Table 3 ) is $1.3 \%$ lower than the mean value of $G_{\text {Ic }}$ (Table 2), which was determined independently from $R$-curves at the end of FPZ development (second square mark in Fig. 8). However, considering the scatter, this difference is not statistically significant. This result gives confidence to the identification method of cohesive law presented in this work.

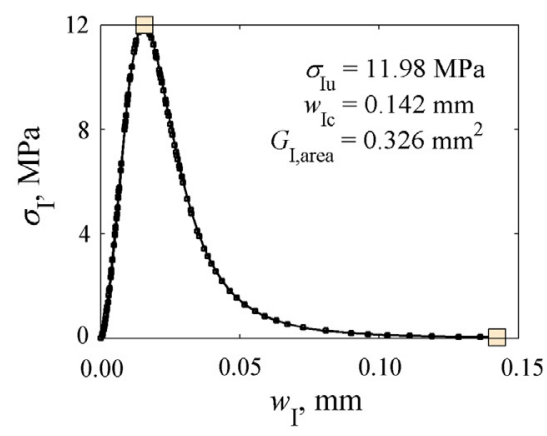

(b)

Fig. 9. (left) $G_{\mathrm{I}}$ versus $w_{\mathrm{I}}$ relation and logistic approximation function; (right) cohesive law $\left(\sigma_{\mathrm{I}}-w_{\mathrm{I}}\right)$. 
Table 3

Mode I cohesive law parameters of $P$. pinaster wood bonded joints.

\begin{tabular}{clll}
\hline Specimen & $G_{\mathrm{I}, \text { area }}(\mathrm{N} / \mathrm{mm})$ & $\sigma_{\mathrm{u}}(\mathrm{MPa})$ & $w_{\mathrm{Ic}}(\mathrm{mm})$ \\
\hline 1 & 0.399 & 7.66 & 0.20 \\
2 & 0.495 & 10.24 & 0.31 \\
3 & 0.484 & 10.85 & 0.15 \\
4 & 0.484 & 7.28 & 0.23 \\
5 & 0.386 & 4.47 & 0.29 \\
6 & 0.217 & 5.20 & 0.18 \\
7 & 0.373 & 9.43 & 0.13 \\
8 & 0.252 & 7.10 & 0.11 \\
9 & 0.289 & 5.67 & 0.41 \\
10 & 0.342 & 9.59 & 0.28 \\
11 & 0.337 & 4.61 & 0.23 \\
Mean & 0.369 & 7.464 & 0.229 \\
Std & 0.094 & 2.307 & 0.089 \\
C.V. ${ }^{1}$ (\%) & 25.5 & 30.9 & 38.9 \\
\hline
\end{tabular}

${ }^{1}$ Coefficient of variation (C.V.).

\section{Conclusions}

This work addresses the experimental identification of the cohesive law in mode I of $P$. pinaster wood bonded joints. The approach combines the double cantilever beam (DCB) test with digital image correlation (DIC) and fibre Bragg grating (FBG) sensors embedded in the glue line. The strain energy release rate in mode I $\left(G_{I}\right)$ is determined from the load-displacement $(P-\delta)$ curve by means of the compliance-based beam method (CBBM). This method relies on the concept of equivalent elastic crack length $\left(a_{\mathrm{e}}\right)$, avoiding crack length monitoring during test. The crack tip opening displacement in mode I $\left(w_{\mathrm{I}}\right)$ was determined by postprocessing local displacements measured by DIC. The cohesive law in mode I $\left(\sigma_{\mathrm{I}}-w_{\mathrm{I}}\right)$ is then obtained by numerical differentiation of the $G_{I}-w_{I}$ relationship. DIC proved to be an efficient method for the experimental evaluation of the cohesive law. The geometric mean value of the wavelength shift of FBG reflected spectral response was used to detect the development of fracture process zone (FPZ), thus allowing the proper selection of experimental range of load $(P)$, load-point displacement $(\delta)$ and CTOD values, over which the identification procedure of cohesive law is build up. The geometric mean value of the wavelength evolution of FBG reflected spectrum proves to be a valuable indicator in delimiting the FPZ development phase. An extension of about $6 \mathrm{~mm}$ of the FPZ on wood bonded joints was estimated. Moreover, it was found that the strain energy release rate at maximum load is a good estimation of $G_{\mathrm{Ic}}$.

\section{Acknowledgments}

This work was supported by European Union Funds (FEDER/ COMPETE - Operational Competitiveness Programme) and by national funds (FCT - Portuguese Foundation for Science and Technology) under the project FCOMP-01-0124-287 FEDER-022692. The authors thank FTC for supporting the work presented in this publication through the research project PTDC/EME/ PME/ 114443/2009 and Ciência 2008 program. The authors thank to Fibersensing for the production of the FBG.

\section{References}

[1] Dugdale DS. Yielding of steel sheets containing slits. J Mech Phys Solids 1960;8:100-4.

[2] Barenblatt GI. The mathematical theory of equilibrium of cracks in brittle fracture. Adv Appl Mech 1962;7:55-129.

[3] Needleman A. A continuum model for void nucleation by inclusion debonding ASME J Appl Mech 1987;54:525-31.

[4] Elices M, Guinea GV, Gomez J, Planas J. The cohesive zone model: advantages, limitations and challenges. Eng Fract Mech 2002;69:137-63.
[5] de Moura MFSF, Morais JL, Dourado NMM. A new data reduction scheme for mode I wood fracture characterization using the DCB test. Eng Fract Mech 2008;75:3852-65.

[6] Silva FGA, Xavier J, Pereira FAM, Morais JJL, Dourado N, de Moura MFSF. Determination of cohesive laws in wood bonded joints under mode I loading using the DCB test. Holzforschung 2013;67:913-22.

[7] Campilho RDSG, Banea MD, Neto JABP, da Silva LFM. Modelling of single-lap joints using cohesive zones models: effect of the cohesive parameters on the output of the simulations. J Adhes 2012;88:513-33.

[8] Andena L, Rink M, Williams JG. Cohesive zone modelling of fracture in polybutene. Eng Fract Mech 2006;73:2476-85.

[9] Slowik V, Villmann B, Bretschneider N, Villmann T. Computational aspects of inverse analyses for determining softening curves of concrete. Comput Method Appl Mech 2006;195:7223-36.

[10] Sørensen BF, Jacobsen EK. Large-scale bridging in composites: R-curves and bridging laws. Compos Part A - Appl Sci 1998;29:1443-51.

[11] Andersson T, Stigh U. The stress-elongation relation for an adhesive layer loaded in peel using equilibrium of energetic forces. Int J Solids Struct 2004:41:413-34.

[12] Dias GF, de Moura MFSF, Chousal JAG, Xavier J. Cohesive laws of composite bonded joints under mode I loading. Compos Struct 2013;106:646-52.

[13] Banea MD, da Silva LFM, Campilho RDSG. Temperature dependence of the fracture toughness of adhesively bonded joints. I Adhes Sci Technol 2010;24:2011-26.

[14] Silva F, Morais J, Dourado N, Xavier J, Pereira FAM, de Moura MFSF. Determination of cohesive laws in wood bonded joints under mode II loading using the ENF test. Int J Adhes Adhes 2014;51:54-61.

[15] Fernandes RMRP, Chousal JAG, de Moura MFSF, Xavier J. Determination of cohesive laws of composite bonded joints under mode II loading. Compos Part B - Eng 2013:52:269-74.

[16] Sousa AMR, Xavier J, Morais JJL, Filipe VMJ, Vaz M. Processing discontinuous displacement fields by a spatio-temporal derivative technique. Opt Laser Eng 2011:49:1402-12.

[17] Xavier J, Oliveira J, Monteiro P, Morais JJL, de Moura MFSF. Direct evaluation of cohesive law in mode I of Pinus pinaster by digital image correlation. Exp Mech 2014;54:829-40.

[18] Sorensen L, Botsis J, Gmür T, Cugnoni J. Delamination detection and characterisation of bridging tractions using long FBG optical sensors. Compos Part A - Appl Sci 2007;38:2087-96.

[19] Xavier J, Morais J, Dourado N, de Moura MFSF. Measurement of mode I and mode II fracture properties of wood-bonded joints. J Adhes Sci Technol 2011;25:2881-95.

[20] Xavier J, Monteiro P, Morais J, Dourado N, de Moura MFSF. Moisture content effects on the fracture characterisation of Pinus pinaster under mode I. J Mater Sci 2014;49:7371-81.

[21] Xavier JC, Garrido NM, Oliveira M, Morais JL, Camanho PP, Pierron F. A comparison between the Iosipescu and off-axis shear test methods for the shear characterization of Pinus Pinaster Ait. Compos Part A - Appl Sci 2004;35:827-40

[22] Xavier J, Oliveira M, Morais J, Pinto J. Measurement of the shear properties of clear wood by the Arcan test. Holzforschung 2009;63:217-25.

[23] Xavier J, Avril S, Pierron F, Morais J. Novel experimental approach for longitudinal-radial stiffness characterisation of clear wood by a single test. Holzforschung 2007;61:573-81.

[24] Xavier J, Avril S, Pierron F, Morais J. Variation of transverse and shear stiffness properties of wood in a tree. Compos Part A - Appl S 2009;40:1953-60.

[25] Pereira J, Xavier J, Morais J, Lousada J. Assessing wood quality by spatial variation of elastic properties within the stem: case study of $P$. pinaster in the transverse plane. Can J Forest Res 2014;44:1-11.

[26] Lancaster P, Salkauskas K. Curve and surface fitting: an introduction. Academic Press; 1986.

[27] Sutton M, Orteu J-J, Schreier H. Image correlation for shape, motion and deformation measurements: basic concepts, theory and applications. Springer; 2009.

[28] ARAMIS, User Manual - Software - v6.0.2-6; 2009.

[29] Xavier J, de Jesus AMP, Morais JJL, Pinto JMT. Stereovision measurements on evaluating the modulus of elasticity of wood by compression tests parallel to the grain. Constr Build Mater 2012;26:207-15.

[30] Sousa AMR, Xavier J, Vaz M, Morais JJL, Filipe VMJ. Cross-correlation and differential technique combination to determine displacement fields. Strain 2011;47:87-98.

[31] Dourado N, Morel S, de Moura MFSF, Valentin G, Morais J. Comparison of fracture properties of two wood species through cohesive crack simulations. Compos Part A - Appl Sci 2008;39:415-27.

[32] Stutz S, Cugnoni J, Botsis J. Crack - fiber sensor interaction and characterization of the bridging tractions in mode I delamination. Eng Fract Mech 2011;78:890-900.

[33] Maciel RS, Frazão O, Morais JJL, Fernandes JRA. Monitoring of non-homogeneous strains in wood glued joints with embedded FBG optical sensors in mode delamination tests. In: Proc. SPIE 8785, 8th Ibero American optics meeting/11th Latin American meeting on optics, lasers, and applications, 8785FQ; 2013.

[34] Jiang J, Liu T, Liu K, Zhang Y. Investigation of peak wavelength detection of fiber Bragg grating with sparse spectral data. Opt Eng 2012;51:034403.

[35] Botsis J, Humbert L, Colpo F, Giaccari P. Embedded fibre Bragg grating sensor for internal strain measurements in polymeric materials. Optics Laser Eng 2005;43:491-510. 